\title{
O.5 Million-Year Pollen Records from Southern Europe
}

Thick lacustrine sequences from southern Europe provide an opportunity to develop complete and high-resolution pollen records spanning multiple glacial-interglacial cycles and showing the response of vegetation to climate variability. The sequences discussed here represent the four longest continuous European pollen records and are located between 39 and $45^{\circ} \mathrm{N}$, forming a WestEast transect: (i) Lac du Bouchet [1,2] $\left(44^{\circ} 55^{\prime} \mathrm{N}, 3^{\circ} 47^{\prime} \mathrm{E} ; 1200 \mathrm{~m}\right.$ above sea level [asl]) and Praclaux [3] (44 ${ }^{\circ} 49^{\prime} \mathrm{N}, 3^{\circ} 50^{\prime} \mathrm{E}$; $1100 \mathrm{~m}$ asl), Massif Central, France. (ii) Valle di Castiglione [4] (41 ${ }^{\circ} 53^{\prime} 30^{\prime \prime} \mathrm{N}$, $12^{\circ} 45^{\prime} 35^{\prime \prime} \mathrm{E}$; $44 \mathrm{~m}$ asl), central Italy. (iii) Ioannina [5,6] $\left(39^{\circ} 40^{\prime} \mathrm{N}, 2^{\circ} 51^{\prime} \mathrm{E} ; 470 \mathrm{~m}\right.$ asl), northwest Greece. (iv) Tenaghi Philippon [7-9] $\left(41^{\circ} 10^{\prime} \mathrm{N}, 2^{\circ} 20^{\prime} \mathrm{E} ; 40 \mathrm{~m}\right.$ asl) northeast Greece.
The published chronostratigraphical scheme for each pollen sequence was used for broad correlations with the marine sequence and assignments to individual isotopic stages. Each data set was then aligned to a target, the SPECMAP stacked $\delta^{18} \mathrm{O}$ record [10] (Fig. 10). 'Glacial-to-deglacial' transitions were used as the tie points on the basis that these transitions have been relatively rapid and the response of vegetation was essentially synchronous within the error estimates for the marine chronology. Given that the sites are located relatively close to glacial tree refugial areas, lags arising from delayed immigration of tree populations were considered to be minimal. This simple step of placing the records on a common timescale, although it eliminates any assessment of leads and lags, greatly facilitates comparison between the different types of proxy evidence in terms of their overall structure and character.

The four pollen sequences display a close similarity to the SPECMAP stack on glacial-interglacial timescales suggesting that the many substages into which the oceanic record is divided are also appropriate for viewing the continental record. It has long been appreciated that the subdivision of Stage 5 is necessary to the understanding of the last interglacial, but the data show a similarly complex structure for earlier deglacial stages, with alternating forest and open vegetation intervals corresponding to the isotopic variations.

While Figure 10 demonstrates the overall similarity between the terrestrial

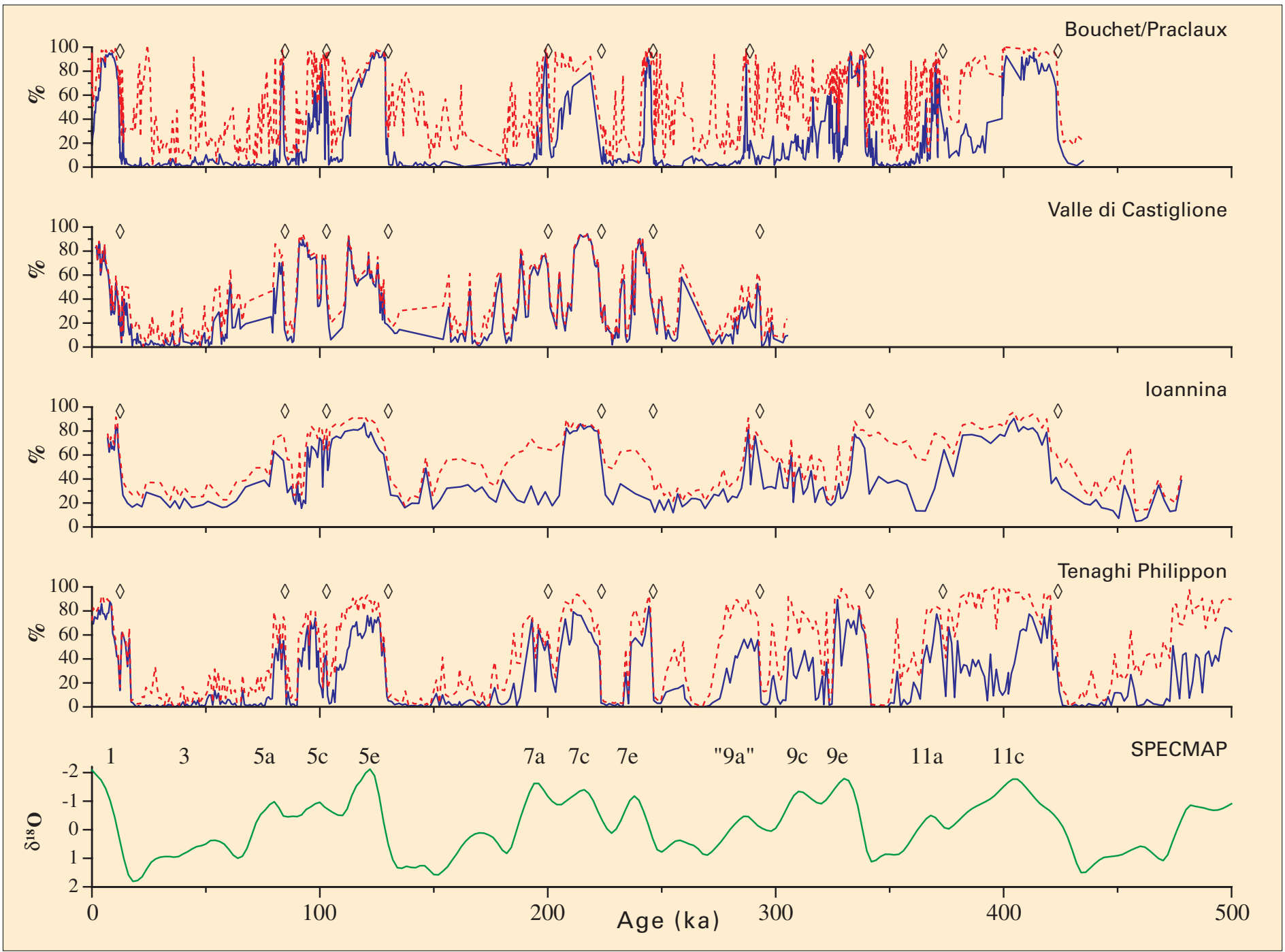

Figure 10: Comparison of terrestrial pollen records and the marine isotope sequence. For the terrestrial records the arboreal (AP) minus Pinus (solid line) curve has been used for correlations and tuning, but the AP curve including Pinus (dotted line) is also shown. Marine isotope stages are indicated. Diamonds show the control points used for tuning. A composite Bouchet / Praclaux record is used here (Bouchet D: 0-110 kyr BP; Bouchet H: 110-287 kyr BP; Praclaux: 287-430 kyr BP). (from Tzedakis, et al. 1997, Earth and Planetary Science Letters 150, 171-176). 
and marine records, it also draws attention to some of the differences between them. One apparent divergence is in the relative amplitude of variation in the indicators used, with Arboreal Pollen (AP) frequencies showing in some cases higher amplitude variations relative to the $\delta^{18} \mathrm{O}$ record. This, to a certain extent, may be an artefact arising from the limitations of the AP percentage signal alone, which provides information on the changes in vegetation structure, but does not reflect compositional changes within and between the periods it defines. More in-depth comparisons may thus require a different measure (such as the paleobioclimatic operator [11]) which can incorporate the additional information. Despite such shortcomings, however, comparison with long and detailed marine records such as ODP 980 [12] suggests that over higher frequencies of variability the AP curves show a closer correspondence to the planktic rather than the benthic isotope records. This suggests the occurrence of rapid climate changes which have had an influence on sea surface temperatures and downstream effects on terrestrial ecosystems, but a moderate impact on global ice volumes. What emerges is that long pollen sequences can be used to add detail to our understanding of the extent and nature of climate variability over orbital as well as sub-orbital frequencies.

\section{P.C. TZEDAKIS}

Department of Geography, University of Cambridge, Cambridge, UK

\section{Andrieu, J.-L. de Beaulieu, M. Reille}

Laboratoire de Botanique historique et Palynologie, URA CNRS, Marseille, France

\section{S. Crowhurst, N.J. Shackleton}

Department of Earth Sciences, University of Cambridge, Cambridge, UK

\section{FolLIERI, D. MAGRI}

Dipartimento di Biologia Vegetale, Università di Roma "La Sapienza", Roma, Italy

\section{H. Hooghiemstra, T.A. WiJmstra}

Department of Palynology and Paleo/Actuo-Ecology, University of Amsterdam, Amsterdam, The Netherlands

\section{References}

[1] M. Reille and J.-L. de Beaulieu, 1990

[2] M. Reille et al., 1998

[3] M. Reille and J.-L. de Beaulieu, 1995

[4] M. Follieri et al., 1988
[5] P.C. Tzedakis, 1993

[6] P.C. Tzedakis, 1994

[7] T.A. Wijmstra, 1969

[8] T.A. Wijmstra and A. Smit, 1976

[9] T.A. Wijmstra and M.C. Groenhart, 1984

[10] J. Imbrie et al., 1984

[11] J. Guiot, 1989

[12] J.F. McManus, et al., 1999

Full references for this article can be found at www.pages.unibe.ch/ publications/newsletters/ref993.html

\section{WORIKSHOP REPORTS}

\section{DFG Program}

\section{Bonn, Germany, 1-2 JuLY, 1999}

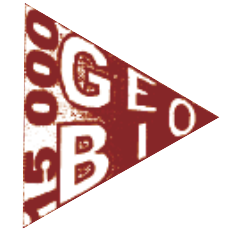

A meeting of the participants in the Deutsche Forschungsgemeineschaft (DFG) priority program 'Changes in the Geosphere-Biosphere during the last 15,000 years (see PAGES News Vol 6. No. 1) was held on July 1 and 2 in Bonn, Germany. Over 40 presentations were made summarizing the progress made in each of the projects funded through the program. These focus on continental and near-shore, marine archives of every kind within and around Germany. The outcomes of the program will be of great interest to PAGES through contributions to PEP III, to Focus 3 themes dealing with human impact on environmental systems, and to the improvement of chronological control for key periods of environmental change. The program will conclude with a major colloquium in November 2000 presenting the results through a series of oral reviews and project-specific posters. This meeting will be co-sponsored by PAGES and the joint intention will be to use the occasion to link the research accomplishments of the program more closely to the international scientific community.

\section{Frank Oldfield}

PAGES IPO, Bern Switzerland

oldfield@pages.unibe.ch

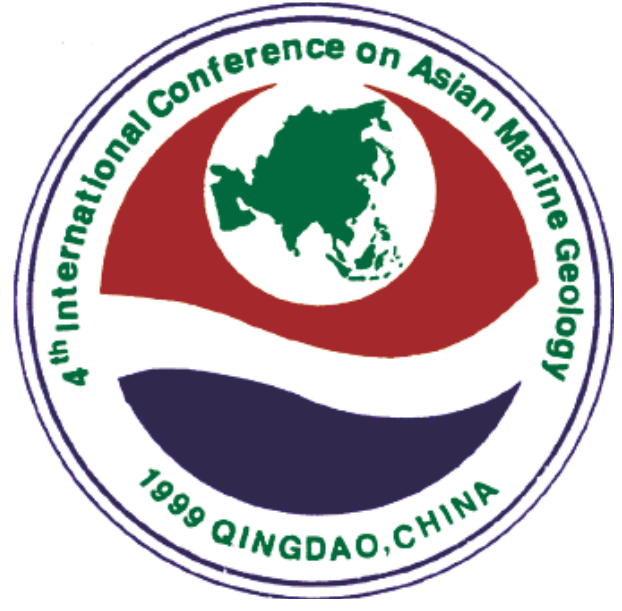

\section{$4^{\text {th }}$ Conference on Asian Marine Geology}

\author{
Qingdao, China, 14-17 October, 1999
}

More than 100 participants, from 18 nations, presented a range of research based primarily on marine sediment records in the Asia-Pacific region. Much of the research presented fell within the PAGES remit, including regional sea surface temperature and salinity reconstructions (Min-Pen Chen - Taiwan marginal seas, Tdamichi Oba - Japanese coastal waters, Yali Sun et al. - Sr measurements in corals). Other topics which received considerable attention included the reconstruction of changes in the Kuroshio boundary current (Pinxian Wang, Hiroshi Ujiie) and sea level changes during the Holocene (Yong Ahn Park, B. Krishna Rao, Fernando Siringan). The Yellow river deposits an enormous sediment load to coastal waters, some $90 \%$ of which is derived from the Chinese Loess Plateau (Yoshiki Saito). It was suggested that high resolution sediment records should be targeted by constraining periods of high sedimentation with accurate dating (Serge Bernier).

The Asian Marine Geology community has grown rapidly since the first meeting in Shanghai in 1988, and is increasingly addressing questions of high resolution, quantitative environmental change of relevance to the PAGES project. The Fifth International Conference on Asian Marine Geology is scheduled to be held in Thailand in 2003.

\section{Keith Alverson}

PAGES International Project Office, Bern, Switzerland alverson@pages.unibe.ch 